\title{
XXI.
}

\section{Ueber den Einfluss des veränderten Luftdruckes auf den menschlichen Organismus.}

Von Dr. R. v. Vivenot jun. in Wien.

Es ist bekannt, dass der mittlere Luftdruck, welchem die uberwiegende Mehrzahl der Menschen auf dieser Erde ausgesetzt ist, einem mittleren Barometerstande von $758 \mathrm{Mm}$. ( $=28$ Par. Zoll), d. h. dem Drucke einer Quecksilbersäule von $758 \mathrm{Mm}$. Höhe, oder einer Wassersäule von 32 Par. Fuss entspricht, und dass mithin der von allen Seiten her auf den Menschen ausgeübte Druck wenn wir mit Foissac*) dem Cubikfuss Luft ein Gewicht von circa $2 \frac{3}{4}$ Loth beilegen - einem mittleren Gewichte von 300 Centnern gleichkommt.

Wenn wir nun diesen Druck, wie er uns durch das Barometer angezeigt wird, genauer analysiren, so finden wir, dass derselbe nicht allein auf Rechnung der atmosphärischen Luft, sondern auch theilweise auf Rechnung der in der Luft enthaltenen Wasserdämpfe kommt, dass derselbe mithin auś 2 Hauptfactoren, 1) aus dem Drucke der trockenen Luft und 2) aus dem Drucke der Wasserdämpfe, i. e. Dunstdrucke besteht. Da nun gemischte Gasarten auf ihre Umgebung gemeinsam drücken, und wir kein Instrument besitzen, welches uns den Antheil der trockenen Luft sowie den in der Atmosphäre enthaltenen Wasserdämpfen zukommenden an dem Gesammtluftdrucke gesondert anzeigen würde: so ist klar, dass nur durch Rechnung diese Sonderung geschehen kann, und dass uns somit der Barometerstand nur die Summe dieser beiden drückenden Factoren, d. i. also den Gesammtluftdruck anzeigen wird. - Bezeichnen wir die trockene Luft mit a, die

-) P. Foissac, Meteorologie mit Rücksicht auf die Lehre vom Cosmos. - Ins Deutsche übersetzt von A. H. Emsmann. Leipzig 1859. S. 307. 
Wasserdämpfe oder den Dunstdruck mit $\mathrm{a}^{\prime}$, so erhielten wir demnach für den Gesammtluftdruck, d. i. Barometerstand b die Formel

$$
\mathrm{b}=\mathrm{a}+\mathrm{a}^{\prime} \text {. }
$$

Da nun der Druck der trockenen Luft mit der Wärme abnimmt, erhöhte Wärme und verminderter Luftdruck aber eine gesteigerte Evaporation der Flussigkeiten auf der Erde, und demnach eine Vermehrung des Dampfgehaltes der Luft zur Folge haben, so ist einleuchtend, dass, je nach der zur Verdampfung vorräthigen Wassermenge, eine mehr oder wenjger vollständige Compensation zwischen Luft- und Dunstdruck stattfinden muss.

Es werden mithin (da jeder Temperatur ein bestimmter Dunstdruck zukommt, welcher, obne dass ein Niederschlag erfolgt, nicht überschritten werden kann) zu Folge eben dieser, bei zureichender Wasserverdampfung stattfindenden vollkommenen Compensation zwischen Luft- und Dunstdruck, selbst zwei durch Breitegrad und Temperatur bedeutend verschiedene Orte einen ganz gleichen Barometerstand nachweisen können, während an jedem dieser Orte dem Luftdrucke und dem Dunstdrucke ein verschiedener Werth entspricht. Substituiren wir also beispielsweise in obiger Formel wirkliche Werthe und setzen wir den Barometerstand $b$ am Niveau des Meeres $=758 \mathrm{Mm}$., so wird, bei einer bestimmten Temperatur, der trockenen Luft a ein Druck von $755 \mathrm{Mm}$. - den Wasserdămplen $a^{\prime}$ hingegen nur ein Druck von $3 \mathrm{Mm}$. entsprechen. Ist nun eine genügende verdampfende Wasserfläche vorhanden, um bei zunehmender Wärme die damit einhergehende Rarefaction der Luft durch eine gesteigerte Verdunstung zu compensiren, so wird der Barometerstand uns fortwährend einen Druck von $758 \mathrm{Mm}$. anzeigen, wenn gleich die Zusammensetzung der auf die Quecksilbersäule drückenden Luft sich in der Weise ändert, dass $a+a^{\prime}$ bald einer Summe aus $754 \mathrm{Mm} .+4 \mathrm{Mm}$., oder aus $748 \mathrm{Mm} .+10 \mathrm{Mm}$., oder aus $738 \mathrm{Mm} .+20 \mathrm{Mm}$. entspricht.

Dass sich dies wirklich also verhalte, und dies verkehrt proportionale Verhältniss $z$ wischen dem Druck der trockenen Luft und dem Dunstruck in der eben beschriebenen Weise stattfinde, beweist das Verbalten des Barometers auf Inseln und an Meeresküsten, wo aus den oben entwjckelten Gründen der Barometerstand 


\section{4}

im Sommer nahezu eben so hoch ist, als im Winter, während ubbereinstimmend hiermit, im Inneren grosser Continente gerade das Gegentheil stattfindet. - So finden wir z. B. im Inneren von Asien (Dove) und in der Wüste Sahara (Kämtz) ein unverhältnissmässiges Sinken des Barometerstandes im Sommer, weil daselbst die hohe Sommertemperatur an sich schon eine Luftverdünnung zur Folge hat, und keine genugende Wasserfläche daselbst verdampfen kann, um dieser Rarefaction das Gleichgewicht zu halten. Mithin wird trotz der hohen Temperatur auch der Dunstdruck ein geringerer sein; - und demnach, da die wechselseitige Compensation zwischen Luft- und Dunstdruck hier nicht erfolgen kann, muss offenbar der Barometerstand ein sehr niederer sein*).

Ich habe diese eben erläuterten Verhältnisse absichtlich etwas ausführlicher hervorgehoben, da sie in ähnlicher Weise bei dem, den Evaporationsgesetzen gehorchenden menschlichen Organismus stattfinden und es einleuchtend ist, dass eine bedeutende Veränderung im Dampfgehalte der Luft wesentliche Veränderungen in dem menschlichen Organismus hervorrufen muss. Da derselbe bei trockener Luft in kurzer Zeit eine grosse Wassermenge durch Verdampfung verliert, und Verdampfung stets mit Temperaturabnahme des verdampfenden Körpers einhergeht, demnach auch dem menschlichen Organismus hierbei Wärme entzogen wird, so wird dieser, wenn er die verloren gegangene Wärme ersetzen will, einen lebhafteren Oxydationsprozess einzuleiten gezwungen sein, - indess bei feuchter Luft das Gegentheil stattinden muss. - Das frühèr angeführte Beispiel der Compensation zwischen Luft- und Dunstdruck hat uns gezeigt, dass eine wesentliche Veränderung in der Mischung der Luftbestandtheile stattfinden kann, ohne dass hierdurch der Luftdruck geändert wird, d. h. ohne, dass wir sie am Barometer abzulesen im Stande sind, und dennoch

*) Der zu Cairo im Monat December 764,0 Mm. betragende Barometerstand fällt in Folge der Dampfarmuth der Luft im Monat Juli auf $755,43 \mathrm{Mm}$. herab. Die Differenz im Luftdrucke dieser zwei Monate beträgt mithin $8,57 \mathrm{Mm}$. Zu Palermo als exquisitem dampfreichen Inselclima finden wir den höchsten monatlichen Luftdruck mit $755,42 \mathrm{Mm}$., den niedrigsten mit $753,30 \mathrm{Mm}$. verzeichnet, wonach sich im Luftdrucke dieser 2 Monate die nur geringe Differenz von $2 \frac{1}{2} \mathrm{Mm}$. ergiebt. 
wird sie durch Veränderung der Temperatur und der Evaporation eine subjectiv fühlbare und objectiv nachweisbare Einwirkung auf den menschlichen Organismus dadurch hervorzurufen im Stande sein. -

Man hat nun auf die hieraus resultirenden Verhältnisse bis jetzt noch wenig Rücksicht genommen, hingegen von jeher mit mehr oder weniger Recht, den Veränderungen im Luftdrucke einen bedeutenden Einfluss auf den menschlichen Organismus zugeschrieben, und diesen Eínfluss nicht bloss bei be deutenden Luftdrucksveränderungen, wie dieselben z. B. beim Ersteigen des Gipfels eines $10-18,000$ Fuss bohen Berges stattfinden, wobei sich der Luftdruck um $\frac{1}{3}$ bis $\frac{1}{2}$ vermindert, sondern auch schon bei den jährlichen, monatlichen und täglichen periodischen und zufälligen Luftdrucksoscillationen, welche wir dem Barometer ablesen, uud bei welchen sich der Luftdruck nur etwa um 10 bis höchstens $30 \mathrm{Mm}$. verändert, zu fühlen und nachweisen zu können geglaubt.

So behaupten insbesondere Laien bei plötzlichen Witterungswechseln die etwa $10-15 \mathrm{Mm}$. betragende Niveau-Veränderung der Quecksilbersäule inres Barometers, also diese Veränderung des Luftdruckes alsogleich gefühlt zu haben.

Auch Aerzte schreiben diesen Luftdrucksveränderungen häufig einen merklichen Einfluss auf das Befinden ihrer Kranken zu, und zwar wird besonders das ,fallende Barometer”, also Verminderung des Luftdruckes, angeschuldigt, stets eine Verschlimmerung der Krankheitssymptome (insbesondere bei Brustkranken) hervorzurufen.

So sagt, um nur einige diesen Ansichten huldigende Autoren anzuführen, unter andern Pelletan*): „Die geringsten Veränderungen, welche im atmosphärischen Drucke vorkommen, haben eine sehr bemerkbare Wirkung auf alle Functionen. Steigt das Barometer, so äussern sich dieselben viel energischer; Menschen und Thiere sind vorzugsweise munter, und in allen ihren Bewegungen gewissermaassen geschickter. Wenn der äussere Druck gesteigert wird, so ist begreiflicher Weise in Folge dieses Zuwachses an Druck die Spannung der häutigen Theile angeregt. Die Flüssig-

*) Traité de Physique T. I. p. 48. 
keiten bewegen sich leichter und schneller (?), wodurch eine genauere und vollständigere Verrichtung aller Functionen, auf welche die Circulation der Flüssigkeiten Einfluss ausübt, bedingt wird. Fällt hingegen das Barometer merklich, so empfinden wir einen gewissen Zwang und eine Mattigkeit, eine Neigung zur Thatlosigkeit, eine Wirkung, die ebenso begreiflich ist, wenn man nur bedenkt, dass die in unserm Körper befindlichen Flüssigkeiten einige Gase enthalten, und ausserdem das Bestreben haben, durch die dem Körper eigenthümliche Temperatur sich zu verflüchtigen; je mehr nun der äussere Druck abnimmt, desto mehr dehnen sich diese Flüssigkeiten aus und drücken von innen auf die Gefässe, wodurch natürlich alle Arten von Circulation beeinträchtigt oder schwächer werden; es stellen sich dann die Zeichen der Vollblutigkeit ein etc."

Auch Foissa ${ }^{*}$ ), dessen Meteorologie ich obiges Citat Pelletan's entnehme, scheint sich dieser Ansicht zuzuneigen, oder wenigstens den zufälligen und periodischen Barometerschwankungen, also den Veränderungen im täglichen Luftdrucke ein grosses Gewicht beizulegen; er sagt:

", Möge Jeder an sich selbst Beobachtungen anstellen, und er wird bald finden, dass die Grösse des Luftdruckes auf sein ganzes körperliches Befinden und auf seine geistige Beweglichkeit nicht ohne Einfluss ist"”...., ,,,Wenn der Mensch, frei von Vorurtheilen und vorgefassten Meinungen, alles das beobachten könnte, was er zu einer bestimmten Zeit empfindet, so würde er bald zur Einsicht gelangen, dass es einen gewissen Barometerstand giebt, bei welchem seine Functionen gewissermaassen mehr Feuer zeigen, bei welchem sein Geist williger, freier, reger ist, bei welchem jede Geistesanstrengung leichter und das Leben voller, frischer wird"” ..... An einer anderen Stelle: ",Fast Niemand befindet sich bei diesen niederen Barometerständen wohl, ausgenommen eine geringe Anzahl trockener, reizbarer, nervöser Naturen und Constitutionen, die wahre Hygrometer oder wahre Violinsaiten sind, die stets gespannt, beim geringsten Streichen des Bogens springen möchten.

*) Foissac, Meteorologie mil Rücksicht auf die Lehre vom Cosmos. Ins Deutsche übersetzt von A. H. Emsmann. S. 390. 
Es ist uns oft begegnet, die Höhe des Barometers angeben zu können bloss aus dem entschiedenen Gefühle einer ungewohnten inneren Kraft, welche jede Geistesanstrengung leicht machte und die Zukunft im reizendsten Lichte erscheinen liess."”

Dass theils subjective Gefuhle, theils selbst mitunter objectiv nachweisbare Veränderungen gleich z eitig mit bedeutenden Wechseln des Niveaus der Quecksilbersäule einhergehen, und der Grad derselben je nach der Empfänglichkeit des Individuums variiren kann, ist unbestreibar. Nur frägt es sich:

Ist nicht die Auffassung, dass diese von Pelletan und Foissac beschriebenen Zufälle Folge der durch das Barometer angezeigten Veränderung des Luftdruckes sind, nicht eine irrige, und sind eben diese Zufälle nicht vielmehr mit grösserem Recht den, mit den Veränderungen des Barometerstandes immer gleichzeitig einhergehenden Veränderungen in den Luftströmungen, in der Temperatur und im Feuchtigkeitsgehalte der Luft zuzuschreiben, als den geringen, etwa $10-30 \mathrm{Mm}$. betragenden Schwankungen im Luftdrucke?

Letzteres gewinnt schon negativ durch den Umstand an grosser. Wahrscheinlichkeit, dass, wie wir gesehen haben, Veränderungen der Temperatur und des Feuchtigkeitsgehaltes der Atmosphäre stattfinden können, welche in eingreifender, fühlbarer und nachweisbarer Weise auf den Organismus einzuwirken im Stande sind, während sich der Gesammtluftdruck, mithin auch der Barometerstand, gar nicht ändert.

Um diese Frage jedoch endgültig beantworten zu können, müssen wir vorerst die reinen Einwirkungen einer Veränderung des Luftruckes zu analysiren trachten, was am besten dadurch geschieht, wenn wir viel grössere Luftdrucksveränderungen, als die, welche uns das Barometer anzeigt, in das Bereich unserer Untersuchung ziehen, und demnach zuerst den Einfluss untersuchen, welchen der Aufenthalt in sehr verdünnter Luft (also z. B. auf $10-18,000$ Fuss hohen Gebirgen), ferner denjenigen, welchen der Aufenthalt in stark verdichteter Luft (z. B. in einem LuftCompressions-Apparate) auf den menschlichen Organismus ausübt, da unter dem Einflusse dieser Extreme die störenden Nebenein- 
nlüsse mehr in den Hintergrund treten, während im Gegensatz die Einwirkung, welche nur der Veränderung im Drucke allein zukommt, in ihrer reinsten Gestalt erscheint.

Der Einfluss des verminderten Luftdruckes giebt sich sehon auf einer Höhe von etwa 5000-6000 Fuss nachweishar zu erkennen, und die durch die Rarefaction der Luft bedingten Zufälle nehmen proportional mit der Luftverdünnung zu. Es sind diese Zufälle mehrfach unter dem Namen der "Bergkrankheit" (mal des montagnes) beschrieben worden.

Die Evaporation ist vermehrt, - - der Organismus verliert durch Haut und Lungen viel Wasser, und zwar sowohl wegen der bedeutenden Verminderung des auf ihm lastenden AtmosphärenDruckes überhaupt, als auch theilweise wegen des, mit der zunehmenden Seehöhe abnehmenden Dampfgehaltes der Luft (Dunstdruck), welcher, da in die höheren Regionen der Luft bereits zu wenig Wasserdampf gelangt, den verminderten Druck der trockenen Luft nicht mehr zu compensiren vermag (der analoge Vorgang, welcher im Sommer in der Wüste von Afrika und im Innern ron Asien stattfindet, und um diese Zeit ein verhältnissmässig bedeutendes Sinken des Barometerstandes veranlasst).

Die mit der gesteigerten Verdunstung einhergehende Temperaturverminderung des Körpers veranlasst denselben einen lebhafteren 0xydationsprozess einzuleiten; - die in demselben Volum weniger Sauerstoff enthaltende Luft nöthigt den Organismus, welcher immer die gleiche Quantität Sauerstoff, d. h. so viel, als er eben braucht, einathmet, - tiefereund hä ufigere Respirationen 2u machen: der Kreislauf wird demnach beschleunigt.

Als Beleg hiefür seien beispielsweise die Beobachtungen Saussure's hier berührt, welcher auf dem Gipfel des Montblane, etwa auf einer Höhe von 12,400 Par. Fuss, nach 4 stündiger Ruhe seine eigenen Pulsschläge und die seiner 2 Führer zählte und fand, dass die Anzahl derselben beziehungsweise 110, 98 und 112 Schläge in der Minute betrug, während nach der Rückkehr nach Chamounix gleichfalls nach 4 stïndiger Ruhe die Anzahl der Pulsschläge bei inm auf 72 , bei den 2 Führern aber auf 49 und 60 in der Minute herabgesunken war. 
Das zwisehen den Gefässen des Organismus und dem normalen Luftdruck bestehende Gleichgewicht wird bei Verminderung des letzteren gestört. In Folge des verminderten Luftdruckes und der dadurch zunehmenden Tension der Gase im lnneren der Gefàsse findet eine Verstärkung deś centrifugalen Druckes des Gefässinhaltes auf die Gefässwandungen statt; die Gefässe erweitern sich, das Blut wird nach jenen Stellen, wo die Nachgiebigkeit am grössten, die Erweiterung den geringsten Widerstand erfährt, also nach der Peripherie des Körpers getrieben. Steigern sich, in Folge der stets zunehmenden Verminderung des Luftdruckes, die eben beschriebenen Zufälle, so finden endlich Berstungen der Wandungen der Gefässe statt, und zwar vorzugsweise an solchen Stellen, wo die der Körperoberfläche zunächst gelegenen Gefässe gleichzeitig das zarteste Gefüge darbieten, - also in den Lungen, an der Mundund Nasensehleimhaut, an der Conjunctiva. Die Blutüberfulliung der peripheren Theile bedingt eine Anschwellung derselben.

Die Gelenkflächen werden bekanntlich nach der Gebruder H. u. E. Weber und später J. Guerin's Untersuchungen nur durch die von aussen her auf sie drückende Luft aneinander gehalten, so zwar, dass die Schwere der Extremitäten gar nicht in Betracht kommt. Vermindert sich nun der Luftdruck, so werden die correspondirenden Gelenkflächen nicht mehr so fest aneinander gepresst, - und hiemit übereinstimmend, erklärt sich auch das von allen Bergesteigern (S a us sure, v. Humboldt, Boussingault) als Symptom der Bergkrankheit angegebene Gefuhl von Müigkeit, welches wohl theilweise, doch nicht allein auf Rechnung des beschwerlichen Bergsteigens zu schieben ist, da es auch von Luftschiffern, welche sich zu bedeutenden Höhen erhoben, gefühlt ward. Ueberdies unterscbejdet sich diese Mildigkeit von der in Folge beschwerlicher Arbeit entstandenen Müdigkeit dadurch, dass sie schon nach einigen Schritten auftritt und bei kurzer Ruhe alsogleich wieder schwindet.

Ein Symptom, welches ich nirgends aufgezeichnet finde, da muthmaasslich keine Beobachtungen in diesem Sinne angestellt wurden, welches aber bei vermindertem Luftdruck, vermöge der bedeutend gesteigerten Evaporation, dem bedeutenden Wasserver- 
luste durch Haut und Lungen zu Folge nothwendig stattfinden muss, wäre schliesslich eine Verminderung der Harnsecretion.

Wir hätten somit als Haupterscheinungen bei bedeutend vermindertem Luftdruck gefunden:

1) Vermehrung der Evaporation.

2) Vermehrten Oxydations-Prozess; demzufolge

3) Beschleunigte Respiration und beschleunigten Puls.

4) Blutandrang nach den peripheren Theilen; demzufolge Erweiterung, ja selbst Berstung der Gefässe daselbst.

5) Geringeres Aneinanderdrücken der correspondirenden Gelenkflächen.

6) Als Folge der vermehrten Evaporation Verminderung der Harnsecretion.

Die eben erörterten Zufälle treten begreiflicher Weise in ihrer auffalligsten Gestalt nur bei bedeutender Verminderung des Luftdruckes auf, und zwar besonders, wenn dieselbe (wie dies z. B. beim Aufsteigen im Luftballon oder beim Bergsteigen auf einer Höhe von 16,000-20,000 Fuss der Fall ist) plötzlich stattfindet. Es unterliegt jedoch keinem $Z$ weifel, und liegt in der eigenthümlichen Acclimatisationsfähigkeit des menschlichen Organismus, dass man sich bis auf einen gewissen Grad allmälig an eine nicht unbedeutende Verminderung des Luftdruckes gewöhnen kann. Den augenfälligsten Beleg hiefür liefern die Bewohner der Hochebenen in den Andesketten und im Himmalaya, welche auf einer Höhe von 8000 bis 12,500 Par. Fuss bei einem Luftdrucke von 540-460 Mm. sich, nach Humboldt u. Bonplandt*), „,der besten Gesundheit erfreuen"”, - und welche sich durch auffallend breiten Brustkorb, gut entwickelte Lungen, langen Rumpf, kurze Extremităten und Fettmangel von ihren nächsten Nachbarn in den Tiefebenen unterscheiden.

*) A. v. Humboldt und A. Bonplandt, Essai sur la Géographie des Plantes 1805, geben den mittleren Barometerstand von Quito mit 20 par. Zoll $(=541,4 \mathrm{Mm}$.), den auf der 12,600 par. Fuss hoch gelegenen Meierei von Antisana mit 17 Zoll 4 Lin. $(=469,21 \mathrm{Mm}$.) an. - Die berühmte Schlacht von Pichincha wurde auf einer Höbe, welche der des Monte hosa nahe kommt, geschlagen. - Man kann annehmen, dass auf einer Höhe von 1000 Fuss der Luftdruck im Mittel um $\frac{1}{30}$, auf einer Höhe von 10000 Fuss also um $\frac{1}{3}$, auf einer Höhe von 18000 Fuss aber bereits um die Hălfte abgenommen hat. 
Was nun den Einfluss eines verstärkten Luftdruckes betrifft, so liegen über denselben noch sehr wenige sichere Beobachtungen vor.

In der Ungebung des todten Meeres, welches bekanntlich 1300 Par. Fuss unter. der Meeresfläche gelegen ist, beträgt der mittlere jährliche Barometerstand $800 \mathrm{Mm}$. Es sind jedoch daselbst noch keine hieher einschlägigen Untersuchungen angestellt worden, ob diese Zunahme des mittleren Luftdruckes um $40 \mathrm{Mm}$. eine in Respiration, Pulsfrequenz etc. nachweisbare Veränderung im Organismus hervorrufe.

Eine schöne Gelegenheit, (wie sie die Natur nicht bietet, da man bis jetzt noch nicht in so bedeutende Tiefen eingedrungen ist) um die reinen Einwirkungen eines vermehrten Luftdruckes zu studiren, bietet der von Tabarié erfundene Luftcompressions-Apparat, welcher in entsprechender Grösse ausgeführt, zum Aufenthalte für mehrere Personen geeignet ist, und welcher in Paris, Lyon, Montpellier und Nizza unter dem Namen ,bain d'air comprimé", - "Bad in verdichteter Luft" zu therapeutischen Zwecken bei Lungenkranken benutzt wird.

Mir ist aus eigener Anschauung nur der zu Nizza befindliche Apparat bekannt, in welchem 10-12 Personen gleichzeitig einem Drucke von $1 \frac{1}{5}$ bis $1 \frac{2}{5}$ Atmosphären, d. i. einem mittleren Drucke von $912-1064 \mathrm{Mm}$. ausgesetzt bleiben können. Dieser Apparat wäre sicherlich geeignet, ein reiches Feld positiver physiologischer und pathologischer Resultate zu eröffinen, - er erlaubt es, die rein e Einwirkung eines vermehrten Luftdruckes, obne gleichzeitiger Störung durch Veränderung der Luftströmungen und der Temperatur, wie dies in der Natur stets zu geschehen pflegt, mathematisch festzustellen.

Leider hat bis jetzt in Nizza noch kein Fachmann, dem es um eine Bereicherung der Wissenschaft ernstlich zu thun gewesen wäre, eine lange fortgesetzte Reihe von Untersuchungen, wie sie der besprochene Apparat und der grosse Krankenzufluss daselbst mit Leichtigkeit ermöglicht, unternommen. Er wird zu Nizza vollkommen planlos, unter nichtärztlicher Leitung, als blosse Geschäftssache angewendet: weder werden von den dortigen Aerzten bestimmte Indicationen für den längeren oder kürzeren Gebrauch 
der von ihnen in die Luftcompressionsbäder geschickten Kranken angegeben, noeh weiss der Leiter der Anstalt, was seinen Badegästen fehlt, noch wann die durch die comprimirte Luft eingeleitete Besserung beginnt und worin dieselbe besteht.

Tabarié und nach inm Pravaz haben bereits vor Jahren eine Reihe von Untersuchungen über den Einfluss der comprimirten Luft unternommen*). Ich habe nun auch zu Nizza an mir selbst und 3 andern Personen hieher einschligige Beobachtungen, - vorzugsweise in Bezug auf Puls- und Respirationsveränderungen gemacht. Die positiven Resultate, die ich hiebei erhielt, werde ich später mittheilen, und ich kann nur bedauern, dass mein zu kurzer Aufenthalt zu Nizza mir nicht erlaubte, meine Beobachtungen weiter auszudehnen und dieselben $6-8$ Wochen hindurch an denselben Personen fortzusetzen, ein Zeitraum, der vollkommen genügt hätte, um auch über die Veränderungen, welche der verstărkte Luftdruck bei pathologischen Zuständen, insbesondere der Respirationsorgane, ausübt, einen sicheren und beweisenden Aufschluss zu erhalten.

Ehe ich auf dieselben eingehe, ist es nothwendig, die Construction des, mit einem 50,000 Francs übersteigenden Kostenaufwande erbauten Apparates in Kürze zu erörtern.

Er ist nach dem Principe der Taucherglocken gebaut, hat, wie nebenstehende Figur im Durchschnitt versinnlicht, die Form eines hohlen Ellipsoides, dessen lăngerer Durchmesser in verticaler, dessen kürzerer Durchmesser in horizontaler Richtung verläuft. Das untere Dritttheil des Ellipsoides (A) ist in die Erde eingesenkt, so dass der über dem Niveau der Erde sichtbare Theil desselben $\left(A^{\prime}\right)$ dadurch die Gestalt einer Glocke erhält. Ein der äusseren Erdoberfläche entsprechend im Innern der Glocke angebrachter hölzerner Fussboden theilt dieselbe in zwei ungleiche Hälften, deren obere, grössere $\left(A^{\prime}\right)$ zum Aufenthalte für die, die comprimirte Luft einathmenden Personen dient. Dieser Boden ist mit einem Teppiche belegt, und trägt 10-12, im Kreise um den im Centrum stehenden Tisch gestellte Stühle. Die Luft der beiden Glockenhälften A

*) Die Original-Abhandlungen über die Arbeiten von Tabarié und Pravaz war ich nicht in der Lage mir zu verschaffen. Die Resultate, welche sie erhielten, sind mir nur aus zerstreuten, theilweise in Foissac's Meteorologie befindlicken Notizen bekannt. 


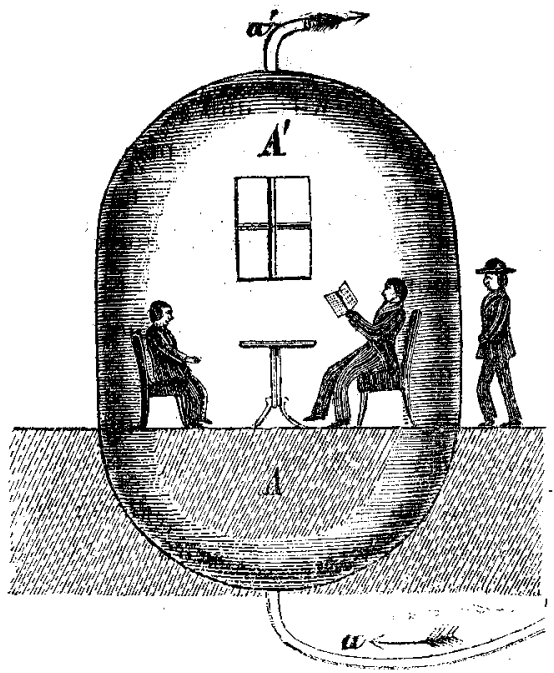

und $\mathrm{A}^{\prime}$ communicirt durch im Fussboden angebrachte Oeffnungen.

Die Glocke ist von Eisen, dessen Dicke der Grösse des auszuhaltenden Druckes entspricht; sie ist mit zolldicken Glasfenstern versehen, theils um das Innere der Glocke zu erleuchten, und den daselbst sitzenden Personen eine beliebige Beschäftigung, als : Lesen, Schreiben etc. zu ermöglichen, theils um dem ausserhalb der Glocke stehenden Leiter und Regulator der Dampfmaschine eine Einsicht auf das im Inneren angebrachte Manometer, welches die Zu- oder Abnahme des Luftdruckes durch einen Zeiger und eine Scale abzulesen erlaubt, - zu ermöglichen. Dem Niveau des äusseren und inneren Fussbodens entsprechend ist eine Thüre zum Eintritt in die Glocke angebracht. Thïre und Fenster sind begreiflicher Weise nach der Innenseite der Glocke zu öffnen; sie sind an der Peripherie mit einem Kaoutschouk-Saume eingefasst, und werden, da der innere Luftdruck stärker ist, derselbe mithin excentrisch auf die Peripherie der Glocke wirkt, schon dadurch mit grosser Gewalt und hermetisch an die ihnen entsprechende Verkleidung angedrilckt.

In diesen eben beschriebenen Apparat wird nun mittelst einer Dampfmaschine durch die Röhre a fortwährend frische verdichtete Luft hineingepresst, welche durch die mittelst eines Ventils verschlossene, am entgegengesetzten Pole der Glocke mündende Röhre $a^{\prime}$ entweichen kann, so dass die in der Glocke sitzenden Personen während der ganzen Dauer des Versuches, welche 2 Stunden betrăgt, fortwăhrend Luft athmen, deren Mischungsverhältniss, unbeschadet der Athmungsprozesse der darin befindlichen Personen, dem der atmosphärischen Luft vollkommen gleichbleibt, und welche sich von derselben nur durch die Verschiedenheit der Dichte unterscheidet. 
Es ist die Einrichtung getroffen, dass die Luft in der Glocke nicht plötzlich, sondern nur allmälig im Verlaufe einer $\frac{1}{2}$ Stunde auf das beabsichtigte Maximum comprimirt wird und zwar in der Weise, dass die in der Glocke sitzenden Personen während ihres 2 stindigen Aufenthaltes in derselben in der ersten halben Stunde einem allmälig zunehmenden, hierauf eine Stunde hindurch auf dem Maximum der Compression stationär bleibenden, und in der letzten halben Stunde wieder allmälig bis zur normalen Dichte abnehmenden Luftdrucke ausgesetzt sind.

Nach dieser Erörterung über die Beschaffenheit des Apparates, muss ich auch noch Einiges über die Vorsichtsmaassregeln vorausschicken, welche ich gebrauchte, um nicht bei den Zahlenwerthen der unten beigefügten Tabelle über die Veränderungen, welche Puls- und Respirationsfrequenz unter dem Einflusse der verdichteten Luft unterliegen, Irrthümer zu veranlassen und Täuschungen $z u$ unterliegen.

Die der Beobachtung unterlegenen 4 Personen begaben sich nie zu Fusse, sondern stets zu Wagen nach der, etwa 20 Minuten von der Stadt Nizza entfernten Villa, in welcher sich der Luftcompressions - Apparat befindet.

Nach der Ankunft wurde noch $\frac{1}{4}$ Stunde im Wartesaale gerastet, und erst dann eine Zählung der Pulsschläge und Respirationen bei normalem Luftdruck vorgenommen.

Die Zählung der Pulsschläge wurde in der Weise vorgenommen, dass die Anzahl der während der ersten Minute beobachteten Pulsschläge nicht notirt wurde, da durch die plötzliche Compression der Radialarterie anfangs stets eine kleine Unregelmässigkeit und Schwankung in den Pulsschlägen derselben eintritt; hierauf wurde, um ganz sicher zu gehen, die Anzahl der Pulsschläge jedes Mal 2 aufeinanderfolgende Minuten hindurch gezählt.

Die Zählung der Respirationen wurde durch Auflegen der Hand auf den Thorax, und zwar derart vorgenommen, dass, der grösseren Genauigkeit halber, auch hier wieder die in der ersten Minute erfolgten Respirationen noch nicht gezählt wurden, und dass ferner die untersuchten Personen während der Zählung ihre Lecture ungestört fortsetzten; letzteres deshalb, um die Aufmerksam- 


\section{5}

keit derselben vom Versuche abzulenken, da besonders Laien, wenn sie ihr Augenmerk auf ihren eigenen Athmungsprocess richten, nicht mehr in ihrer normalen, ruhigen Weise, sondern meist tiefer und langsamer respiriren.

Die auf obige Weise bei normalem Luftdrucke ausgeführten Versuche wurden ebenso und mit denselben Cautelen nach $1 \frac{1}{2}$ stündigem Verweilen in der comprimirten Luft, $d . h$. nach $\frac{1}{2}$ stïndiger Einwirkung des sich allmälig verdichtenden und 1 stündiger Einwirkung des auf dem Maximum der Verdichtung verweilenden Luftdruckes ausgeführt.

Die Versuche wurden immer an denselben 4 Herren, welche in den Tafeln mit $\mathrm{A}, \mathrm{D}$, J und $\mathrm{V}$ bezeichnet sind, und zwar an 8 nacheinander folgenden Tagen (den 16. bis 23. December) vor dem Einnehmen des Mittagmahles, von 12 Uhr Mittags bis $2 \mathrm{Uhr}$ Nachmittags wiederhoblt. Am 7. Tage unterblieb die Zählung, da ich durch Unwohlsein, sie an diesem Tage vorzunehmen, verhindert war. Die 3 andern Herren kamen jedoch auch an diesem Tage in gewohnter Weise.

Die mittlere Temperatur der Luft und mithin auch die der Glocke betrug zur Zeit der Versuche von 12 Uhr Mittags bis 2 Uhr Nachmittags 11,05 Cels. - Der normale Luftdruck im Mittel $770,87 \mathrm{Mm}$. Da nun der letztere bei den unten beschriebenen Versuchen nur um $\frac{1}{5}$ vermehrt wurde, so betrug somit das Maximum, auf welchem der Luftdruck 1 Stunde hindurch (von

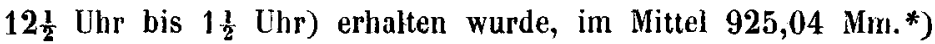

Zur Vervollständigung der Tafel habe ich nebst der Anzahl der Pulsschläge und Respirationen bei normaler und comprimirter Luft, so wie der sich daraus ergebenden Differenz auch noch den Monatstag, den an diesen Tagen beobachteten normalen Luftdruck, d. h. den Barometerstand und die Luftemperatur dieser Tage angegeben. - Auch habe ich zu den Anfangsbuchstaben der Namen das Alter der betreffenden Personen und die Diagnose der Krankheit, wegen welcher sie das verdichtete Luftbad gebrauchten, beigefügt.

*) Die Verdichtung der Luft auf circa $1064 \mathrm{Mm}$., d. i. auf $1 \frac{2}{5}$ Atmosphären geschieht in einer, neben der eben beschriebenen aufgestellten, kleineren Glocke, deren Wände dem utszulzaltenden grösseren Drucke gemäss dicker construirt sind und deren innerer haum den Aufenthalt von nur 2-3 Personen gestattet. 


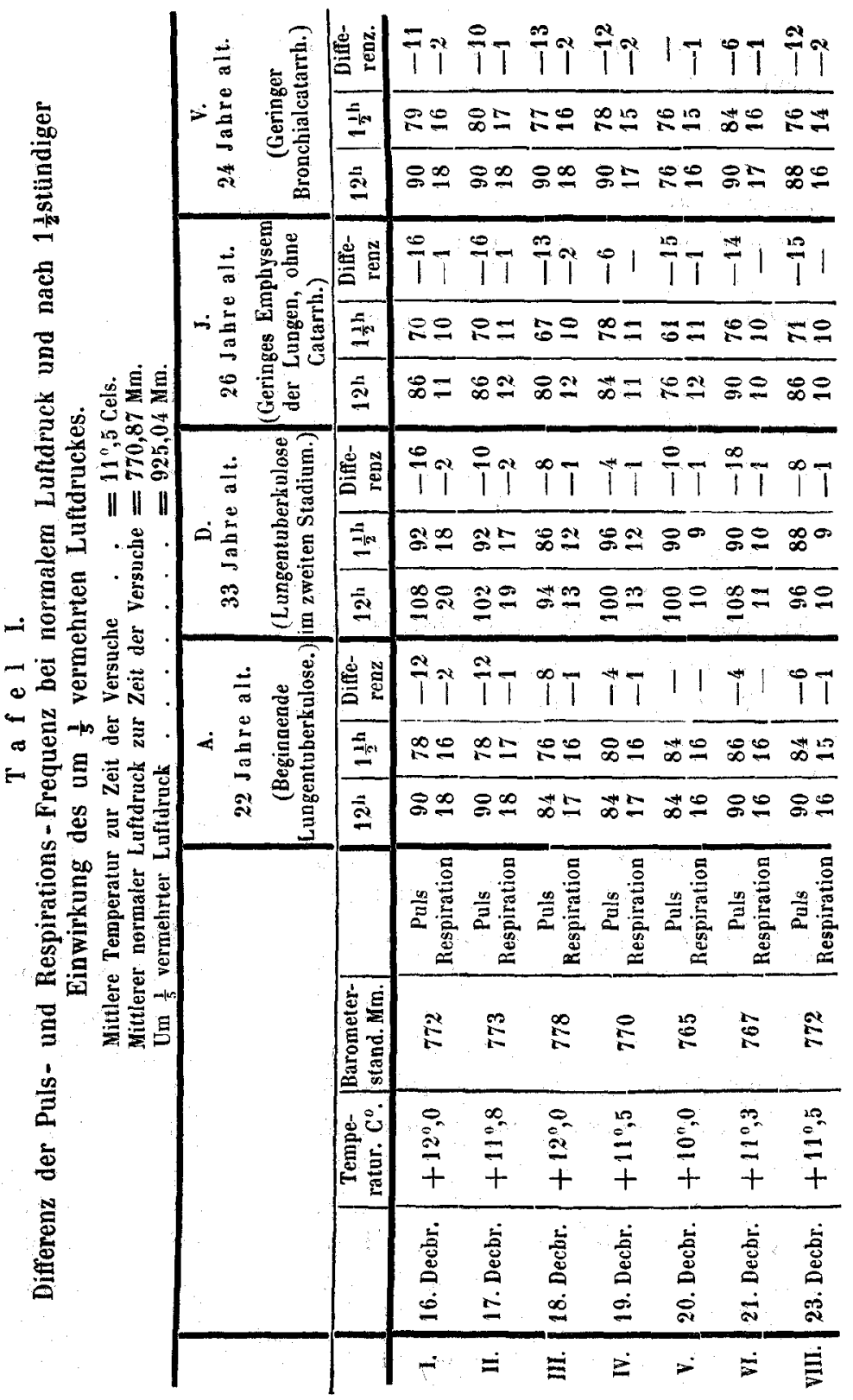




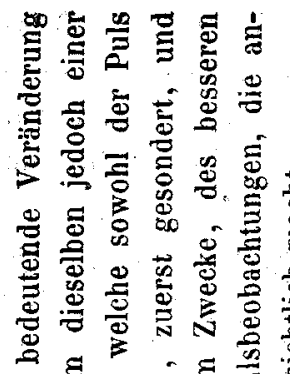

\&

.

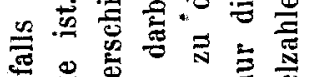

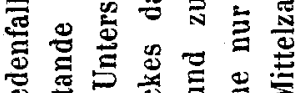

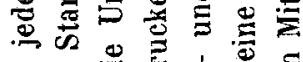

क

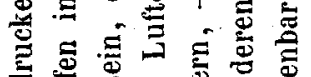

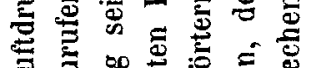

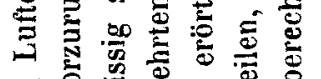

की

包 夏

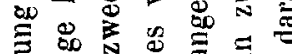

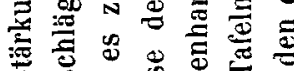

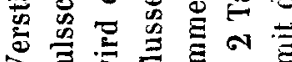

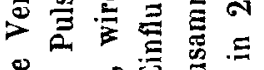

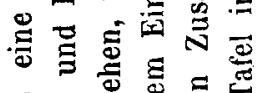

๓

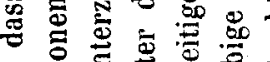

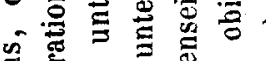

章

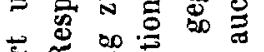

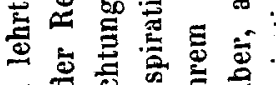

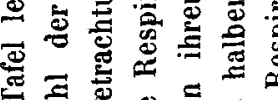

$\circlearrowleft$ 㐘

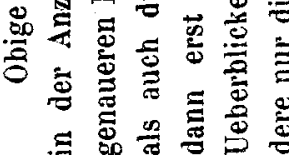

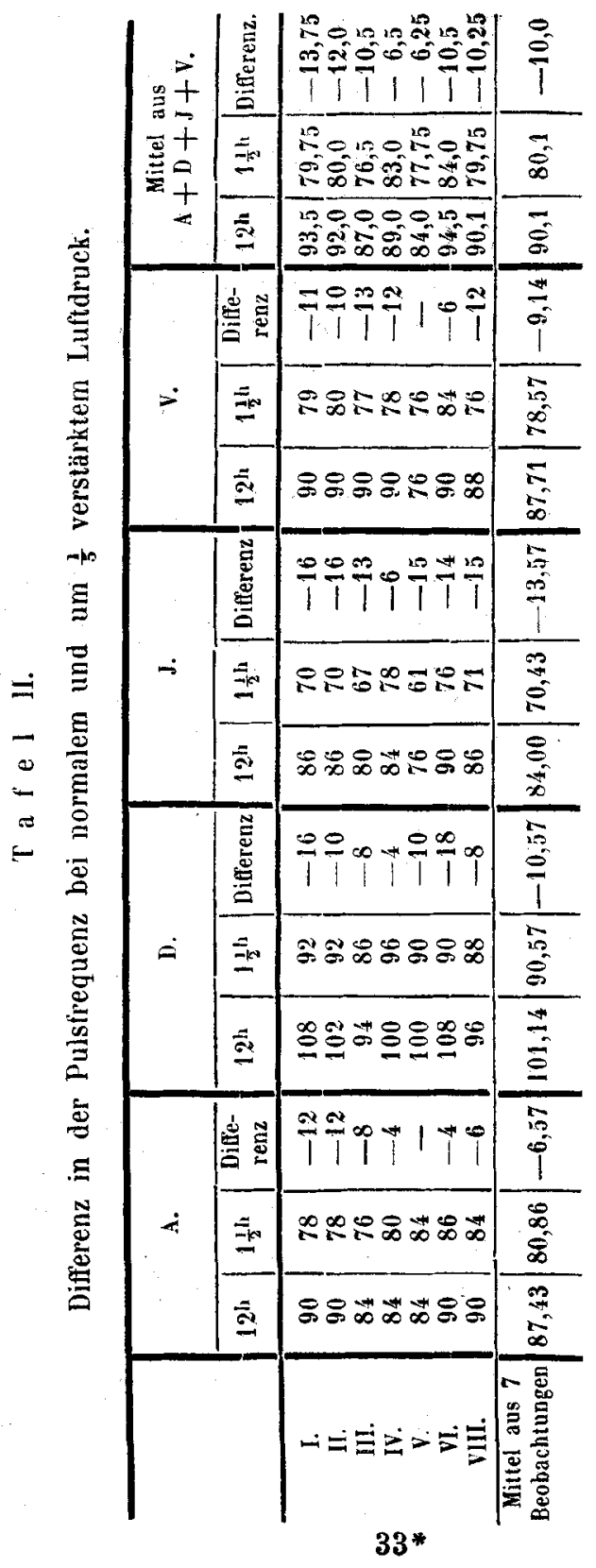


Wir entnehmen der Tafel II., welche die Differenz in der Pulsfrequenz bei normalem Luftdruck $\left(770,87 \mathrm{Mm}\right.$.) und nach $1 \frac{1}{2}$ stündiger Einwirkung eines um $\frac{1}{5}$, d. i. um $154,17 \mathrm{Mm}$. verstärkten, also $925,04 \mathrm{Mm}$. betragenden Luftdruckes ersichtlich macht, im Allgemeinen Folgendes:

1) Die verdichtete Luft bewirkt eine Verlangsamung des Pulses. Unter 28 Beobachtungen wurde der Puls 26 mal verlangsamt und nur 2 mal blieb derselbe unverändert. Die höchste Verlangsamung betrug 18 Pulsschlage in der Minute; als mittlere Verlangsamung (aus 28 Beobachtungen) ergaben sich 10,0 Pulsschläge.

2) Die Einwirkung ist nicht bei allen Individuen gleich gross.

Die grösste Retardation des Pulses zeigte Herr J (Emphysem geringen Grades, ohne Catarrh) mit 13,57, - nächst ihm finden wir Herrn D (Lungentuberculose zweiten Grades) mit 10,57, hierauf Herrn V (leichten Bronchial-Catarrh) mit 9,14 - und endlich Herrn A (beginnende Lungentuberculose) mit 6,57 Schlägen mittlerer Puls - Retardation in der Minute.

3) Die Einwirkung ist bei ein und demselben Individuum nicht jedesmal gleich gross.

Am grössten scheint sie im Beginne zu sein, und mit der häufigen Wiederhohlung der Versuche scheint die Empfänglichkeit abzunehmen. Wir sehen dies sowohl aus den bei den einzelnen Versuchen angegebenen Zahlen, als auch aus den hieraus resultirenden Mittelzahlen, welche beim ersten Versuch eine mittlere Verlangsamung von 13,75, beim letzten Versuch aber nur von 10,25 Pulsschlägen in der Minute ergaben.

4) Diese Puls-Verlangsamung dauert, meinen übereinstimmenden Beobachtungen zu Folge, auch unter normalem Luftdrucke noch wenigstens $\frac{1}{2}$ - auch $1 \frac{1}{2}$ Stunden (wahrscheinlich oft noch länger) fort.

Betrachten wir nun den Einfluss der um $\frac{1}{5}$, d. i. 154,17 Mm. verdichteten Luft auf die Anzahl der Respirationen. 


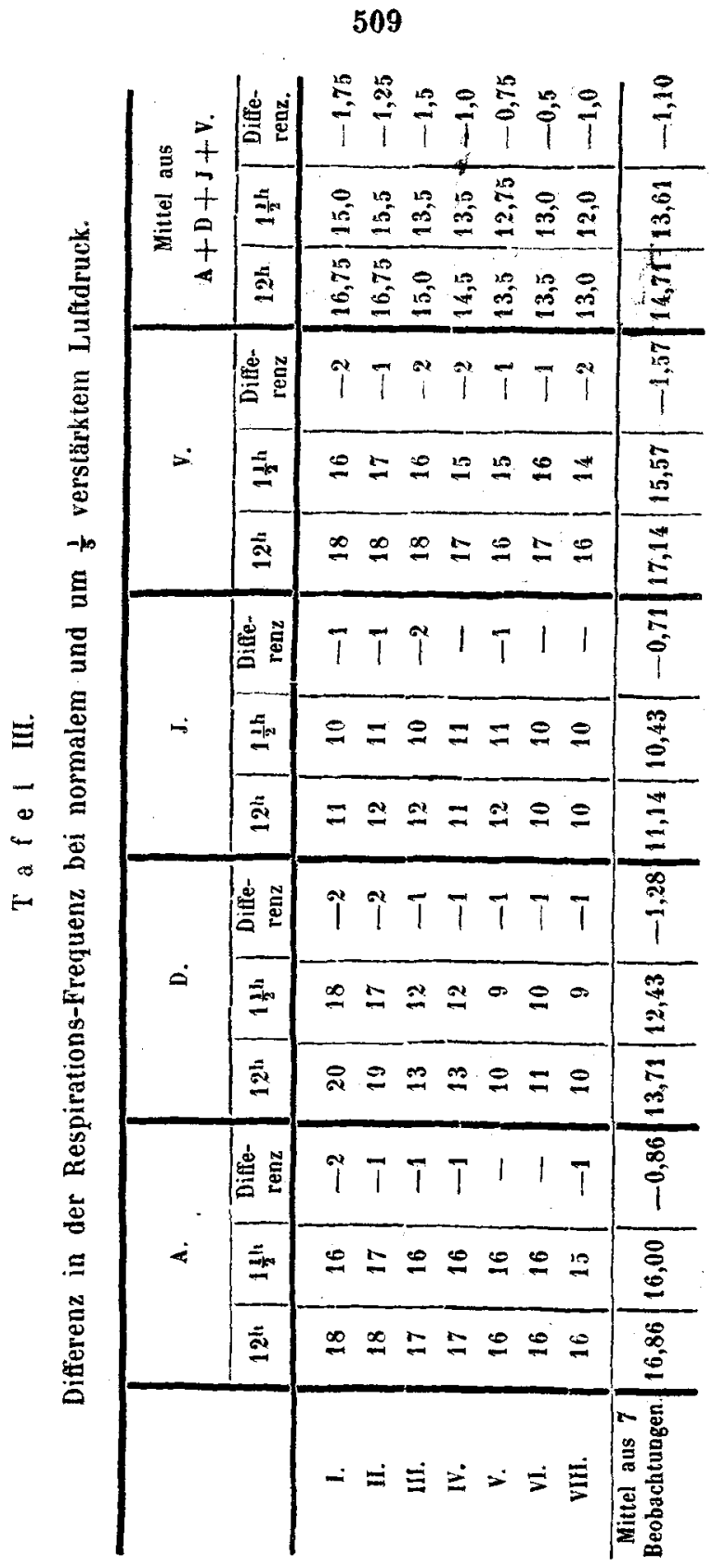


Auch hier finden wir ganz analoge Verhăltnisse, wie die fruher für die Pulsfrequenz erörterten, und zwar:

1) Die verdichtete (uft bewirkt eine Verlangsamung der Respirationen. Unter 28 Beobachtungen wurde die Respiration 23 mal verlangsamt, 5 mal blieb sich die Anzahl der Respirationen bei normalem und bei verstärktem Luftdruck gleich. Die böchste Verlangsamung betrug 2 Respirationen, die mittlere Verlangsamung 1,1 Respirationen in der Minute.

2) Auch hier finden wir, dass die Einwirkung der Luftyerdichtung sich nicht beì allen Individuen gleichmässig äussert. Am stärksten finden wir sie bei $V$ (leichter Bronchialcatarrh) mit 1,57 mittlerer Respirations-Verlangsamung in der Minute, während diese im Mittel bei $D$ (Lungentuberculose zweiten Grades) 1,28 , bei $A$ (beginnende Lungentuberculose) nur 0,86 , und bei $J$ (Emphysem der Lungen) nur 0,71 in der Minute betrug.

3) Sehen wir hier in besonders auffallender und übereinstimmender Weise den eigenthümlichen Einfluss, welchen die $1 \frac{1}{2}$ stündige Einwirkung der verdichteten Luft auf die Respiration ausübt. Jeder der 4 Herren athmete schon beim Beginne des letzten Versuches, also noch unter normalem Luftdruck, weniger häufig als vor dem ersten Versuche. Während die mittlere Anzahl der Respirationen vor dem ersten Versuche 16,75 betrug und durch die verdichtete Luft während des ersten Versuches im Mittel auf 15,0 herabgesetzt wurde, finden wir am letzten Tage die Anzahl der Respirationen schon bei normalem Luftruck im Mittel auf 13,0 , bei verstärktem Luftdruck aber auf 12,0 gesunken.

Am eclatantesten zeigt uns dies Herr D., dessen 20 Respirationen in der Minute nach dem ersten Verweilen in verdichteter Luft auf 18 sanken. Am zweiten Tage hatte er hereits vor dem Versuche nur 19 Respirationen, nach demselben aber 17, - am dritten Tage respirirte er bei normalem luftrucke nur 13 mal, bei verdichtetem Luftdrucke aber $12 \mathrm{mal}$, - am achten Tage endlich kam er mit 10 und verliess mit 9 Respirationen in der Minute die Glocke. Die Anzabl seiner Respirationen war mithin binnen 8 Tagen von 20 auf 9 , also um 11, d. i. um mehr als die Hälfte vermindert worden. - Dasselbe, doch in weniger auf- 
fallender Weise, finden wir bei den ilbrigen 3 Personen $\mathrm{V}$, A und $J$, deren Respirationsanzahl unter normalem Luftdrucke vor dem ersten Versuche respective 18, 18 und 11, - und nach dem ersten Versuche 16,16 und 10 betrug: am Tage des letzten Versuches aber schon bei normalem Luftdrucke auf 16, 16 und 10, - bei verstärktem Luftdrucke aber auf 14,15 und 10 gesunken war.

Es findet also auch hier unzweifelhaft eine über die Dauer des Versuches hinausreichende Nachwirkung der verdichteten Luft auf den Respirationsprozess statt.

Kehren wir nun zur Tafel I. zurück und vergleichen wir, auf Grundlage der eben einzeln für Puls und Respiration gepflogenen Erörterungen den Einfluss, welchen die verdichtete Luft gleichzeitig auf Puls und Respiration ausübt, so ergiebt sich Folgendes:

1) Die verdichtete Luft übt auf Puls und Respiration gleichzeitig eine, mit der Stärke des Luftdruckes zunehmende, verlangsamende Wirkung aus; und zwar ist die Verlangsamung eine um so grössere, je mehr die Anzahl der Pulsschläge und Respirationen sich von der normalen, dem Bedürfnisse des Individuums entsprechenden Anzahl entfernt.

2) Daher finden wir auch die Verlangsamung bei den ersten Anwendungen als eine grössere: je mehr die schon früher erörterte, wie es scheint längere Zeit nachhaltige Einwirkung der verdichteten Luft die abnorm beschleunigten Pulse und Respirationen zur Norm zurückfïihrt, desto geringer wird augenscheinlich ihre Einwirkung. Da nun eine Verlangsamung von Puls und Respiration nicht in's Unendliche statifinden kann, so muss offenbar endlich ein Stadium eintreten, in welchem die comprimirte Luft keine Verlangsamung mehr hervorrufen wird, - in welchem der Organismus seinen Athmungsprozess, den ihm durch die verdichtete Luft gebotenen Verhältnissen entsprechend, regulirt hat (siehe Tafel $I$. Versuch V. Herr A.).

Wir erhalten durch obige Zahlen auch wieder eine Bestätigung der aus Reignault's und Reiset's Versuchen*) hervor-

*) Reiggault und Reiset fanden, dass Thiere, welche längere Zeit reinen 
gehenden Thatsache, dass eine vermehrte Zuftuhrung von Sauerstoff keineswegs einen vermehrten Oxydationsprozess zur Folge habe, sondern dass der Organismus stets gleich viel, d. i. so viel Sauerstoff einathme, als er eben bedarf, und er mithin die Anzahl seiner Athemzilge je nach der vorhandenen Sauerstoffmenge regulirt. Ein gesunder Mensch, welcher also unter dem normalen Luftdrucke von circa $760 \mathrm{Mm}$. täglich eine bestimmte Sauerstoffmenge zu verbrauchen gewohnt ist, wird unter dem Einflusse der auf $925 \mathrm{Mm}$. verdichteten Luft weniger tief und langsamer athmen müssen, da ihm, wenn er in gewohnter Weise fortathmen würde, zu viel Sauerstoff, d. h. mehr als er bedarf, zugefuhrt wird. Anders verhält es sich aber bei einem kranken, z. B. hochgradig tuberculösen Individuum, welches zu Folge theilweiser Zerstörung seiner Lungen in normaler Luft factisch $z u$ wenig Sauerst off erhalten würde, wenn es in normaler Weise zu respiriren fortführe. Ein solches Individuum ist daher gezwungen, selbst wenn die Luft die für Gesunde hinreichende Sauerstoffmenge enthält, in der Weise zu respiriren, wie dies Gesunde nur auf hohen Bergen in rareficirter Luft thun, um deren Sauerstoffmangel zu ersetzen, - nämlich: möglichst schnell und tief einzuathmen, um dadurch ein grösstmögliches Volum atmosphärischer Luft der Lungenoberfläche zuzuführen, - eine Respirationsweise, welche offenbar mit einer Beschleunigung des Kreislaufes einhergeht. -

Es mag nun diese Art und Weise zu athmen (wie dies Gesunde auf hohen Bergen, Lungenkranke aber unter allen Verhältnissen zu thun pflegen), da sie eine angestrengtere Thätigkeit der Lungen in Anspruch nimmt, jedenfalls zur besseren Entwicklung der Lungen beitragen, - und mag allerdings dadurch bei gesunden Individuen, besonders wenn sie schon von Kindheit an, z. B. durch beständigen Aufenthalt auf hohen Gebirgen einer sauerstoffärmeren, tiefere und schnellere Athemzìge erfordernden Luft ausgesetzt bleiben, - die Entwicklung der Lungentuberculose verhindern können, wie dies aus Mühry's climatologi-

Sauerstoff einathmeten, cben so viel Kohlensäure ausathmen, als dies in gewöhnlicher atmosphärischer Luft der Fall. 


\section{3}

schen Untersuchungen hervorgeht, welchen zu Folge die Phthisis mit zunehmender Höhe abnehme, ja auf gewisser Höhe gar nicht mehr vorkomme; und nach welchem die Bewohner der 8000 bis 12,000 Fuss hohen Hochebenen der Andesketten und des Himmalaya sehr selten von Tuberculose der Lungen befallen werden und wie bereits erwähnt, einen sehr breiten Thorax mit sehr entwickelten Lungen autweisen.

Es würde hieraus etwa hervorgehen, dass man Kindern tuberculöser Eltern, gleichsam als Prophylacticum gegen die Entwicklung der Lungentuberculose, einen mehrjährigen Aufenthalt auf Gebirgen anempfehlen solle.

Unmöglich aber kann ich der Ansicht beipflichten, nach welcher rareficirte, d. h. sauerstoffarmere Luft bei schon vorhandener oder wohl gar schon. weit vorgeschrittener Lungentuberculose als Heilmittel gegen dieselbe angewendet werden soll, da zu jeder Art von Heilung Ruhe des kranken Organs als Hauptbedingung erscheint, rareficirte luft aber, welche beim Gesunden schon eine künstliche Dyspnoe hervorruft, beim Lungenkranken die schon vorhandene Dyspnoe, den Sauerstoff-Hunger, nur noch vermehrt.

Ich hann im Gegentheil nur durch verdichtete Luft die Indicationen erfüllt sehen, durch welche bei Lungenkranken die vorhandene Dyspnoe vermindert, und durch Regulirung und Verlangsamung des Respirationsprozesses auch eine Verlangsamung des Kreislaufes und des gesammten Stoffwechsels hervorgerufen wird.

Wird durch den oben beschriebenen Lufteompressions-Apparat einem Lungenkranken, dessen Lungencapacităt in Folge der Krankheit vermindert wurde, welcher also bei normaler Luftdichtigkeit zu wenig Sauerstoff erhält, in dem gleichen Volum comprimirter Luft eine grössere Sauerstoffmenge, $d$. h. so viel als er eben braucht, zugeführt, so wird er offenbar bei langsameren und weniger tiefen Inspirationen, wenn nicht mehr, doch sicher ebenso viel Sauerstoff erhalten, als dies früher bei seinen frequenten und tiefen Athemzügen der Fall war. Da nun hiedurch jedenfalls sowohl ein Zustand von grösserer Ruhe in den Lungen selbst, als 


\section{4}

auch secundär im ganzen Organismus hervorgerufen wird, so kann hiemit schon eine Bedingung zur Heilung der Tuberculose, so wie der Lungenkrankheiten überhaupt, gegeben sein.

Die Anwendung des eben Gesagten auf einen concreten Fall dürfte die eben erläuterten Verhältnisse noch klarer zu machen im Stande sein. Nehmen wir beispielsweise an, ein gesundes Individuum bedürfe 100 Theile Sauerstoff in der Minute, die es in 10 Athemzügen zu Kohlensäure verbrennt; es bekommt mithin bei jeder Inspiration 10 Theile Sauerstoff. - Nun wird dasselbe von Lungentuberculose befallen; ein Theil seiner Lungen wird in Folge dessen für den Respirationsprozess unbrauchbar; es würde nun, wenn es in seiner früheren normalen Weise $\mathrm{zu}$ athmen fortführe, in 10 Athemzügen nicht mehr die benöthigten 100 Theile Sauerstoff, sondern deren etwa nur 50, also die Hälfte zu wenig, erhalten. - Es muss nun, um dieses Minus von 50 Theilen Sauerstoff zu ersetzen, tiefer und häufiger respiriren, und wird daher in dem gegebenen Falle $20 \mathrm{mal}$ in der Minute athmen müssen, um die nöthigen 100 Theile Sauerstoff in sich aufnehmen zu können. Schreitet nun die Zerstörung seiner Lungen continuirlich fort, so muss offenbar endlich ein Stadium eintreten, in welchem es die Respiration nicht mehr zu acceleriren vermag, und dieses Maximum der schnellen und tiefen Respirationen selbst nicht mehr ausreicht, ihm 100 Theile Sauerstaff in der Minute zuzuführen, in welchem also in Folge des mangelhaften Oxydationsprozesses Cyanose und heftige Dyspnoe eintreten wird. Nehmen wir an, dass es unter solchen Verbältnissen nur 80 Theile Sauerstoff, folglich 20 Theile zu wenig aufzunehmen im Stande sei. Führe ich ihm aber nun eine Luft $z u$, welche bei gleichbleibendem Volum (also in $x$ Cubikzoll) statt 100 Theile 130 Theile Sauerstoff enthält, so erhält er bei gleichbleibender Frequenz und Tiefe der Athemzüge in der Minute 30 Theile Sauerstof mehr als unter den früheren Verhältnissen. - Um die eben bei der forcirtesten Respiration hinreichende Sauerstoffmenge zu erhalten, hätte er nur 20 Theile mehr benöthigt, da er früher, wie wir oben sagten, hiebei 20 Theile zu wenig erhielt. - Da ihm aber die comprimirte Lult 30 Theile mehr, also $10 \mathrm{zu}$ viel zuführt, so 
kommt dies Plus an Sauerstoff der Tiefe und Frequenz seiner Respiration zu Gute. Er wird deshalb in verdichteter Luft ruhiger und langsamer respiriren, und demzufolge wird auch die Beschleunigung der Pulsfrequenz abnehmen.

Wir haben bis jetzt nur immer eine, und zwar die chemische Einwirkung des verdichteten Luftdruckes, welche hauptsächlich in vermehrter Sauers to ff $z$ ufuhr bei einem kleineren Volum Luft bestand, im Auge gehabt.

Eine zweite, ebenfalls in Rechnung zu bringende Einwirkung des verdichteten Luftdruckes aber ist die, welche einer Verstärkung des Druckes ïberhaupt als solcher zukommt.

Wie wir wissen, kommt die Schwere der über 'uns lastenden Luftsäule im Niveau des Meeres im Mittel einer Quecksilberhöhe von $760 \mathrm{Mm}$. , d. i. einem Gewichte von eirca 300 Centnern gleich. Da nun unser Organismus, um dies auf ihn von allen Seiten driickende Gewicht $\mathrm{zu}$ tragen, - entsprechend eingerichtet ist, so muss eine bedeutende Vermehrung oder Verminderung dieses Druckes an sich auch eine bedeutende Veränderung in den dem veränderten Drucke unterliegenden Theilen ausüben. Die Veränderungen, welche ein bedeutend verminderler Druck der Luftsäule auf den Organismus hervorruft, haben wir bereits kennen gelernt. Ein vermehrter Druck muss sich daher offenbar durch entgegengesetzte Wirkungen äussern.

Diese finden wir nun nicht bloss in Folge theoretischer Reflexionen, sondern auch durch die Resultate der hierauf in dem oben' beschriebenen Luftcompressions-Apparate angestellten Versuche bestätigt.

Die Evaporation an der Haut und Lungenoberfläche wird durch Verstärkung des Luftdruckes vermindert. Ueber das Verhalten der Schweisssecretion, welche nach Tabarié und Pravaz vermindert ist, habe ich keine Erfahrung, da bei der zur Zeit der Versuche im Mittel 11,05 Cels. betragenden Luftemperatur die Bedingung zur Schweisssecretion überhaupt fehlte. Doch fand ich an mir selbst und an den 3 andern Herrn mit Tabarié und Pravaz - die Secretion der Lungenschleimhaut entschieden vermindert. 
Die auffallendste Folge der verminderten Evaporation aber äusserte sich übereinstimmend an mir und den andern Herren, während der ganzen Versuchsreihe, durch gesteigerte Nierenfunction, d. i. durch unmittelbar $\mathrm{nach}$ dem Luftbade auftretende massenhafte Harnsecretion, welche bei mir, als ich Nizza verliess, sofort wieder aufhörte, - mithin nur auf Rechnung der Einwirkung der comprimirten Luft geschoben werden kann.

Der Antheil, welcher bei diesen Zufällen auf die mit der Luftverdichtung einhergehende Vermehrung des Dunstdruckes zu schieben ist, - dürfte jedenfalls ein sehr untergeordneter sein. Der mittlere Barometerstand zur Zeit der Versuche betrug, wie wir bemerkt haben, $771 \mathrm{Mm}$; die damalige mittlere Temperatur hingegen $11,5^{\circ}$ Cels. Dieser Temperatur entspricht nahezu ein Dunstdruck von 11,5 Mm., welche, vom Gesammtluftdruck abgezogen, für die trockene Luft einen Druck von 759,5 Mm. ergeben (unsere anfangs gegebene Formel würde hier lauten: $\mathrm{b}-\mathrm{a}^{\prime}=\mathrm{a}$, das heisst $771-11,5 \mathrm{Mm} .=759,5 \mathrm{Mm}$.). Da nun der um $\frac{1}{5}$ vermehrte Luftdruck in dem Luftcompressions-Apparate $925,1 \mathrm{Mm}$. betrug, so fallen hievon $911,3 \mathrm{Mm}$. auf den Druck der trockenen Luft und $13,8 \mathrm{Mm}$. auf den Dunstdruck (nach unserer Formel $a+a^{\prime}=b$, auf den gegebenen Fall angewendet: $911,3+13,8 \mathrm{Mm} .=925,1 \mathrm{Mm}$.). Der Dunstdruck wurde also im Ganzen nur sehr unbedeutend, nämlich nur um $2,3 \mathrm{Mm}$. vermehrt.

$\mathrm{Da}$, wie wir gesehen haben, die rareficirte Luft in Folge des verminderten Druckes auf den Organismus und der hiedurch zunehmenden Tension der Gase im Inneren der Gefässe ein centrifugales Zuströmen des Blutes gegen die peripheren Theile bedingt, welches sich in den Organen, in welchen die zarten Blutgefässe so zu sagen mit der atmosphärischen Luft in Berührung kommen, also in den Lungen, in Nase, Mund, Ohren, Augen in höchster Potenz bis zur Apoplexie derselben stejgern kann: so muss offenbar der verstärkte Luftdruck sich in einer gegentheiligen Wirkung äussern, und eine Verdrängung des Blutes von den peripheren Theilen, zu welchen auch die Lungenschleimhaut gezählt werden muss, bedingen. Verdichtete Luft muss also vorhandene Congestionen jener Theile zu vermindern im Stande sein. 


\section{7}

Und sie wurde auch bei ähnlichen Zufällen (Haemoptoë; Pneumonie etc.) von Pravaz mit gïnstigem Erfolge angewendel. Letzterer hat eine Reihe von hieher einschlagigen therapeutischen Erfolgen mit theils vollständiger Heilung (bei Bronchitis etc.) theils wenigstens mit auffallender Besserung (bei Lungentuberculose) veröffentlicht.

Auch zu Nizza wurde mir dergleichen versichert, welch letztere Aussagen ich jedoch, da die therapeutische Anwendung daselbst zu oberflächlich und planlos erfolgt, nur mit dem gebührenden Vorbehalte aufnehmen will.

Was nun noch das subjective Gefuhl betriff, welches man unter dem Einflusse der verdichteten Luft empfindet, so hatte ich, mit Ausnahme eines, während der ganzen Dauer der Luftverdichtung fortbestehenden Gefühles von Druck in den Ohren (dasselbe Gefühl, welches sich, als ich mich in London in der Taucherglocke niederliess, bei mir zu einer stets zunehmenden, schmerzhaften Empfindung im Ohre, ja unter dem Drucke einiger Atmosphären zu vollkommener Taubheit steigerte) gar keine $\mathrm{Em}$ pfindung, welche eine Veränderung des Luftdruckes hätte ahnen lassen. Die ubrigen, mit mir dem Einflusse der verdichteten Luft ausgesetzt gewesenen Herren hatten selbst nicht einmal das Gefuhl von Druck in den Ohren, - emplanden also gar nichts.

Fassen wir nun die Einwirkungen des vermehrten Luftdruckes in Kürze zusammen, so finden wir:

1) Verlangsamung des Pulses.

2) Verlangsamung der Respiration.

3) Verminderte Evaporation an der Haut- und Lungenoberfläche, - mithin verminderte Secretion aller auf der Körperoberfläche mündenden Secrete. Als Folge hievon

4) Vermehrte Harnsecretion.

5) Verdrängung des Blutes aus den peripheren Theilen, also Verminderung von etwa daselbst vorhandenen Congestionen.

Wir haben nach diesen Erörterungen somit gefunden, dass sich der Einfluss eines verstärkten oder verminderten Luftdruckes auf den menschlichen Organismus im Wesentlichen aussert: durch Verminderung oder Vermehrung der Evaporation, - hiemit zu- 
sammenhängend durch Vermehrung oder Verminderung der Harnsecretion, - durch Verlangsamung oder Beschleunigung des Pulses und der Respiration - endlich durch Verdrängung des Blutes von, oder Zuströmen desselben zu den peripheren Theilen.

Nachdem uns somit die reinen Einwirkungen eines veränderten Luftdruckes nunmehr bekannt sind, können wir nun zu der im Beginne dieses Aufsatzes angeregten Frage: „ob die von Pelletan, Foissac etc. gleichzeitig mit Barometerschwankungen einhergehend beobachteten, theils objectiven Erscheinungen, theils subjectiven Gefühle den Veränderungen im atmosphärischen Drucke zuzuschreiben seien?" zurückkehren, und zu deren Beantwortung schreiten.

Wenn wir auf die bedingende Ursache eingehen, welche ein Steigen oder Fallen, des Barometers, - also eine Verdichtung oder Verdünnung der Luft - veranlasst, so müssen wir sie in einer Veränderung der Luftströmungen, der Temperatur und des Dampfgehaltes der Luft suchen. Wie bekannt, ist der barometrische, thermische und hygrometrische Werth der Winde ein verschiedener. Am constantesten und gleichmässigsten bleibt sich derselbe in solchen Gegenden, wo die, von allen Seiten mit nahezu gleich viel Feuchtigkeit gesättigt zuströmende Luft eine Gleichmässigkeit in den atmosphärischen Verhältnissen hervorruft, welche sich durch das bekannte Characteristicum des seeklima's: "Ausschliessung aller extremen Verhältnisse" äussert, und sich dadurch so wesentlich von dem Continental-Clima unterscheidet, welches im Gegensatz zu dieser Gleichmässigkeit des Seeoder Inselclima's ,extreme Verhätnisse aller Art”, bald Kälte und Trockenheit, bald Wärme und Feuchtigkeit bietet, je nachdem die zugefübrte Luft aus kalten und trockenen oder aus warmen und feuchten Gegenden berüberweht. Da nun Kälte eine Verdichtung, Wärme hingegen eine Verdünnung der Luft bedingt, so wird, wenn keine hinreichende, durch Vermehrung oder Verminderung des Dampfgehaltes eine Compensation herbeiführende Wasserfläche vorhanden ist, bei kalten Winden das Barometer steigen, bei warmen hingegen fallen, und zwar dies um so mehr, 


\section{9}

je greller die mit diesem Wechsel verbundenen Temperaturs- und Feuchtigkeitsschwankungen sind.

Es bedarf nun bei einem ähnlichen, in unseren Gegenden z. B. so häufig vorkommenden, plötzlichen Umschlagen des Südwest-Windes in den Nordost, bei der gleichzeitig hiemit einhergehenden Aenderung der Wärme in Kälte und der feuchten Luft in trockene, keines sehr subtilen Empfindungsvermögens, um die hierdurch im Organismus hervorgebrachten Veränderungen in eben der Weise, wie sie Foissac, Pelletan und Andere bei Luftdrucksveränderungen beschrieben, zu fühlen und wahrzunehmen, - auch bedarl es meiner Ansicht nach hiezu nicht erst noch einer geringen Luftschwankung, um von dieser, und nur von dieser allein eine fühlbare und sichtbare Einwirkung auf den Organismus zu erwarten.

Weht anhaltend Nordost-Wind, so wird die hierdurch erzengte bedeutende Trockenheit der Luft eine gesteigerte Evaporation der Perspirationsfeuchtigkeiten an der Haut- und Lungen-0berfläche des menschlichen Organismus einleiten; da, wie wir wissen, Verdampfung stets eine Temperaturerniedrigung des verdampfenden Körpers bedingt, so wird durch die bei trockener Luft gesteigerte Evaporation der Organismus veranlasst, einen gesteigerten Oxydationsprozess einzuleiten, um sich auf seiner normalen Temperatur' zu erhalten. Es ergiebt sich mithin schon als Folge der trockenen Luft eine Beschleunigung des Pulses und der Respiration. - Da nun ein Suldwind und ein Nordwind nicht gleiche Temperatur mitbringen können, sondern ersterer Erwärmung, letzterer krkaltung der Luft bedingt, so ist begreiflich, dass dieser Temperatırunterschied sowohl alsogleich subjectiv gefühlt, als objectiv nachweisbar sein wird, da Wärme (besonders feuchte Wärme) eine erschlaffende, den Kreislauf verlangsamende, - Kälte hingegen (and zwar besonders trockene Kälte) eine, sowohl mächtig erregende Wirkung auf das Nervensystem, als auch eine beschleunigende Wirkung auf das Gefässsystem ausüben wird.

Da nun in unseren ( sich mehr weniger einem ContinentalClima hinneigenden) Gegenden Trockenheit der Luft, Kälte derselben und Nordost-Wind stets gleichzeitig mit steigendem Baro- 
meter einhergehen, - Feuchtigkeit der Luft, Wärme und SüdwestWinde dagegen stets von einem fallen des Barometers begleitet sind, - diese atmospharischen Veränderungen aber an sich, selbst wenn der Luftdruck sich immer gleich bliebe, jene Wirkungen auf den Organismus ausiiben, welche Pelletan, Foissac und Andere den Schwankungen im Drucke der Atmosphäre zuschreiben; - so ist es klar, dass eben diese Verănderungen des Druckes hiebei, wenn nicht gar keine, doch wenigstens eine sehr untergeordnete und vermöge ihrer Unbedeutendheit der Untersuchung kaum zugängliche Rolle spielen.

Eben so erklärt die mit trockener Kälte einhergehende Erregung des Nerven- und Gefässsystems das von Pelletan und Foissac dem "hohen Barometerstande" zugeschriebene Gefühl von ,grösserer Energie, von Munterkeit, von Geschicklichkeit und Geistesfrische", - ein Gefühl, welches, wie jeder mässige Reiz bei den meisten gesunden Menschen, als ein angenehmes empfunden werden wird. Die entgegengesetzte Empfindung wird man jedoch bei solchen Individuen treffen, welche gegen trockene Luft und den. stets mit derselben einhergehenden raschen Temperaturwechsel sehr empfindlich reagiren, also vorzugsweise bei Brustkranken, bei welchen das Einathmen kalter, trockener Luft im Gegensatz zur milden feuchtwarmen Luft einen allzu grossen Reizzustand ihrer kranken Organe hervorruft.

Nicht der durch niederen Barometerstand angezeigte verminderte Luftdruck ist es demnach, welcher bei feuchter Wärme durch Erschlaffung der Nerven- und Gefässthätigkeit, ein Gefühl von Mattigkeit, von Körper- und Geistes-Trägheit hervorruft.

Eben so wenig ist es die Verstärkung des Luftdruckes, welche, wie Viele meinen, sich an Me eresküsten, auf Inseln von wohlthätigem Einfluss für Brustkranke erweist, - diese Vermehrung des Druckes ist zu unbedeutend, um, bei dem Vorhandensein so vieler anderer, stärker wirkender Einflüsse, hier in Betracht kommen zu können - sondern die aus der Luftfeuchtigkeit resultirende gleichmässigere Temperatur, der für die Mehrzahl derselben in vielseitiger Beziehung angemessene, wohlthätige und behagliche vermehrte Feuchtigkeitsgehalt der. Luft, welcher sich oft selbst bei 


\section{1}

den entgegengesetztesten Winden nur wenig ändert, da fortwährend jeder dieser Winde mit Wasserdampf geschwängerte Luftschichten mit sich fuhren muss, und die Luft demnach nie so trocken werden kann, wie dies auf Continenten der Fall ist, wenn daselbst der von der Seeseite herwehende Wind plötzlich in den trockenen Continentalwind umspringt.

Da wir überdiess anfangs gesehen haben, dass der Fall denkbar sei, dass bedeutende Witterungswechsel stattfinden können, und dabei in Folge der gegenseitigen Compensation des Luft- und Dunstdruckes der Barometerstand sich kaum verändert, wir aber trotzdem alle jene Erscheinungen an uns beobachten werden, welche man dem veränderten Luftdrucke zuschreiben zu mussen glaubte: - da ferner im Gegensatz hiezu (und dies scheint mir ein schwer in die Wagschaale fallendes Factum) weder ich, noch die 3 andern mit mir einem Luftdrucke von $925 \mathrm{Mm}$. ausgesetzten Herren, ausser dem bereits erwähnten geringen Druckgefühle in den Ohren - von dieser bedeutenden Druckverstärkung, welche die grössten Barometerschwankungen wenigstens $5 \mathrm{mal}$ ubertriff, nicht das geringste Gefuhl hatten, indem sich unter diesen Verhältnissen die Temperatur gleichblieb, und hiebei keine die Temperatur ändernde Luftströmung stattfand; - da wir ferner úberhaupt gefunden haben, dass die Druckveränderungen in der Atmosphäre sich durch ganz andere Einwirkungen äussern als die, welche man gleichzeitig mit Veränderungen des Barometerstandes $z u$ beobachten Gelegenheit hat: so halte ich den Schluss für gerechtfertigt, mit Richerand*) auszusprechen: "Die Veränderungen in der Schwere der Luft, welche das Barometer anzeigt, sind für den Physiologen und selbst für den Arzt von sehr wenig Bedeutung", - oder mit anderen Worten: Wäre es denkbar, dass bei gleichbleibender Temperatur, gleichbleibender Luftströmung und unverändertem Feuchtigkeitsgehalte der Luft, eine derartige Veränderung im Luftdrucke, wie dieselbe den täglichen und jährlichen Barometerschwankungen entspricht, stattfände, so würde deren Einwirkung auf den mensch-

") Nouveaux éléments de physiologie. T. II. p. 4. 10ième édition. Archiv f. pathol. Anat. Bu. XIX. IIf. s u. 6. 
lichen Organismus, um nicht $\mathrm{zu}$ sagen gar keine, doch jedenfalls eine derart subtile sein, dass sie selbst von den empfindlichsten Personen, weder subjectiv gefuhlt, noch viel weaiger objectiv nachgewiesen werden würde.

\section{XXII.}

\section{Ueber die Farbenblindheit durch Genuss der Santonsăure.}

Von Dr. Edm. Hose.

Bei dem Naeliweis, den ich früher*) gefuhrt, dass als der wesentlichste Grund des sogenannten Gelbsehens, das nach dem Genuss der Wurmblüthenpräparate auftritt, das Verlöschen des violetten Endes in der Farbenreihe des Spektrums, mit anderen Worten eine Licht- und Farben-Parese der Netzhaut, die sieh gegen die Einwirkung der kürzesten der sichtbaren Aetherwetlen zuerst ausspricht, erscheine, drängten sich viele Fragen auf, die eine fernere Beobachtung exforderten, ganz davon abgesehen, dass eine weitere Bestätigung dieses Resultates wünschenswerth war.

Wie verhält es sich mit der einmal gleichfalls nachgewiesenen Verkurzung an rothen Ende, die später bei einer andern Methode weniger berücksichtigt werden konnte? Ist sie ebenso constant, oder unter welchen Umständen tritt sie ein? Hält sie ebenso, wie die Veränderung am andern Ende, die ganze Zeit der Narkose an, oder wann und wie lange erscheint sie?

Steht damit etwa das mehrmals beobachtete violetsehen in Verbindung, oder untel welchen Bedingungen tritt dies ein? Sehliesst es das Gelbsehen aus oder wechselt es mit ihm? Ist es sein Vorgänger oder Begleiter? Lst es uberhaupt von der Einwirkung des Lichtes abhängig oder gar nicht dadurch bedingt?

*) Dieses Archiv, Bd. XVI S. 233; Bd. XVHII. S. 15. oder in: De Santonico. Diss, inate. med. Jun. 1858, Berolini. 